\title{
Aprisionamento materno e escolarização dos filhos
}

\author{
Claudia Stella
}

\begin{abstract}
Resumo
O objetivo deste artigo é refletir sobre o impacto do aprisionamento materno na vida escolar dos filhos. Este trabalho está ancorado na coleta de histórias de vida de filhos de mulheres presas. A amostra foi constituída por quatro rapazes e duas moças, com média de idade de 21 anos, que moravam com a própria mãe ou com a família dela quando da prisão materna e se encontravam no processo de escolarização. A partir das entrevistas, verificamos que a prisão materna pode deixar a criança em situação de vulnerabilidade, o que reflete na socialização promovida pela escola, assumindo aspectos como: a criança pode estar emocionalmente tão envolvida com questões de ordem familiar que apresenta pouca disponibilidade e energia para o seu processo de aprendizagem; pode também não ter um acompanhamento sistemático do seu desenvolvimento escolar, já que talvez não possua um adulto significativo que apóie e valorize sua escolarização.
\end{abstract}

Palavras chaves: Ausência materna, rendimento escolar, filhos.

\begin{abstract}
The objective of this article is to reflect on the impact of mother's imprisonment on children's life at school. This work is based on the life histories of children of imprisoned women. The sample was constituted by four young males and two young females, with the average age of 21 years, who were in the schooling process and lived with their mothers or with their mother's families at the time they went to prison. From the interviews we see that mother's imprisonment can leave the child in a vulnerable situation, which reflects on the socialization promoted by the school and may take aspects such as: the child may be so involved with his mother's imprisonment that she or he has limited availability to learn; she or he may not be supervised in his schooling process, since perhaps he doesn't have a significant adult who supports and values her or his schooling.
\end{abstract}

Mother's aprisionment and children's schooling

Keywords: Mother absence, academic achivement, sons.

\section{Encarcelamiento materno y escolarización de los hijos}

\begin{abstract}
Resumen
El objetivo de este artículo es reflexionar sobre el impacto del encarcelamiento materno en la vida escolar de los hijos. Este trabajo tiene por base la recopilación de historias de vida de hijos de mujeres presas. La muestra está constituida por seis jóvenes, cuatro hombres y dos mujeres, con edad promedio de 21 años, que vivían con la propia madre o con su familia durante el encarcelamiento materno y se encontraban en proceso de escolarización. A partir de las entrevistas verificamos que el encarcelamiento materno puede dejar a los niños en situación de vulnerabilidad, hecho que se refleja en la sociabilización promovida por la escuela y que puede asumir aspectos como: el niño puede estar tan envuelto emocionalmente con cuestiones de carácter familiar, que presenta poca disponibilidad y energía para su proceso de aprendizaje; puede no tener acompañamiento sistemático de su desarrollo escolar, ya que tal vez no tenga un adulto significativo que apoye y valore su escolarización.
\end{abstract}

Palabras-clave: ausencia materna, desempeño escolar, hijos. 


\section{Introdução}

O abandono voluntário ou involuntário de crianças e a separação entre pais e filhos são temas que permeiam não só o imaginário social, mas também constituem um problema social efetivo para as Ciências Humanas e Sociais.

Esse problema provocou, entre outros, os estudos sobre as ações de adolescentes "problemáticos", como os "delinquentes" estudados por Winnicott (1984) e os resultados da ausência materna em crianças e adolescentes problematizados por Bowlby (1993) e Spitz (1995).

Assim, trabalhos que têm como tema as separações entre pais/mães e filhos e suas consequências para as crianças não são propriamente uma novidade. Porém, as separações de pais e filhos, especialmente de mães e filhos, ocasionadas pela prisão têm sido pouco estudadas no Brasil e no mundo (Stella, 2005).

Os filhos e filhas de homens e mulheres presos são como uma população esquecida, não só pela instituição escolar, mas também pelos meios acadêmicos e pela sociedade em geral: pouco sabemos quem são, onde estão e como são (se é que são) atendidos pela escola e, especialmente, não sabemos de que necessitam e quais suas reais dificuldades.

Esse desconhecimento evidencia não somente o caráter excludente da sociedade e, consequentemente, a ausência de políticas públicas específicas para essas pessoas, como também o despreparo de profissionais, professores e instituições, incluindo a escola, para atender e lidar com essa população.

Tanto os filhos de homens presos como de mulheres presas podem enfrentar dificuldades semelhantes - por exemplo, a quebra de vínculos e a estigmatização - porém, nesta pesquisa, os sujeitos privilegiados foram os filhos das mulheres presas, opção que se deve à existência de significativas diferenças entre a prisão materna e a paterna, baseadas na verificação de que, ao longo da história, as crianças sempre estiveram ao encargo das mulheres. Os dados estatísticos da literatura internacional mostram que, quando o pai é preso, a maioria das crianças continua sendo cuidada pela mãe. Contudo, quando da prisão materna, somente $10 \%$ das crianças continuam sendo cuidadas pelos companheiros das mães (Gabel, 1992). O mesmo dado pode ser observado no censo penitenciário paulista, no qual se verifica que a guarda da maioria dos filhos dos homens é assumida por suas companheiras (86,9\%), enquanto que apenas $19,5 \%$ dos filhos de mulheres presas ficam com seus companheiros (Censo Penitenciário, 2002).

A prisão materna tem outros efeitos sobre as crianças: a mudança de seu cuidador primário, a perda de apoio emocional e, muitas vezes, do apoio financeiro, podendo, nesse tipo de separação, serem atingidas de uma forma mais intensa, especialmente quando saem de seu ambiente familiar e entram em um ambiente mais amplo como, por exemplo, a escola, uma vez que os encargos maternos com as crianças ultrapassam o espaço doméstico e as mulheres têm também a responsabilidade do acompanhamento escolar de seus filhos. Por isso, a separação mãe-filho pela prisão não pode ser tratada como outra separação (morte, divórcio), pois possui características específicas, quais sejam, a mudança do papel social da mãe e a influência do significado social da instituição prisional.

Ainstituição escolar - importante meio de socialização do indivíduo - tem sido estudada sob vários aspectos: como promotora de vínculos sociais importantes; como responsável pelo atendimento de crianças "fora dos padrões sociais", por exemplo aquelas com necessidades educacionais especiais e as "problemáticas".

O papel da escola, como meio, e a compreensão do processo de socialização dos filhos de mulheres presas por ela promovido - tema proposto neste trabalho - ainda não foram tratados diretamente pela literatura nacional e internacional às quais tivemos acesso. Porém, alguns problemas escolares ("déficit de atenção", indisciplina, abandono e fracasso escolar) são relatados na literatura como sendo frequentes a essa população (Fritsch \& Burkhead, 1981; Marshall \& Binkiewic, 1992).

Como uma instituição criada para manutenção de uma dada sociedade e cultura, a escola também desempenha um papel de reprodutora dos padrões sociais e, com isso, pode acolher ou excluir os indivíduos em seu meio. Em seu interior, o processo de socialização ocorre por meio de uma complexa trama de relações que contribuem nas interpretações e significações que o indivíduo faz da cultura e da sociedade nas quais está inserido, o que pode favorecer ou dificultar a posterior inserção social desta criança no mundo das relações de trabalho e das relações sociais em geral.

Do exposto até aqui, o objetivo deste artigo é refletir sbre o impacto do aprisionamento materno na vida escolar dos filhos, dando voz a um de seus protagonistas, isto é, às pessoas que enfrentaram e enfrentam a separação materna pela prisão e, a partir daí, entender a influência da prisão materna e do impacto social produzido por ela nos diversos tipos de relações estabelecidas pelos indivíduos, especialmente em seu processo de socialização escolar.

\section{A Instituição Escolar}

A escola se constitui como um meio importante de socialização e, na sociedade moderna, tem um papel fundamental na vida e no desenvolvimento dos indivíduos, incluindo a transmissão de valores e papéis culturais, representando concretamente uma ruptura com o ambiente familiar.

Mais ampla e menos afetiva que a família, a escola, na sociedade atual, participa ativamente do processo de socialização secundária pela qual passa o indivíduo. "A socialização secundária é a interiorização de "submundos" institucionais ou baseados em instituições. A extensão e caráter destes são portanto determinados pela complexidade da divisão do trabalho e a concomitante distribuição social do trabalho" (Berger \& Luckmann, 1978, p. 185).

Para os autores, então, a socialização secundária implica na divisão institucional baseada na divisão do 
trabalho, com a existência de "submundos institucionais", isto é, de grupos nos quais a convivência humana é institucionalizada com um propósito específico.

A socialização secundária pressupõe uma socialização primária anterior, da qual o indivíduo participa com uma personalidade formada e com um mundo interiorizado. Algumas crises na passagem da socialização primária para a socialização secundária manifestadas pelo indivíduo são causadas por seu reconhecimento de que o mundo e as posturas sociais que lhe foram apresentadas na família possuem uma conotação social particular.

A socialização primária influencia a interiorização da socialização secundária, uma vez que o indivíduo internaliza, isto é, subjetiva a realidade objetiva, por meio da atribuição de significados que outras representações fazem desta realidade. Desse modo, a socialização secundária pode ser menos arraigada na consciência e, consequentemente, mais vulnerável.

"A mulher, os filhos e a secretária reafirmam solenemente cada dia que o indivíduo é um homem importante ou um fracassado sem esperanças. As tias solteiras, as cozinheiras e os ascensoristas formam graus variados de apoio a esta reafirmação" (Berger \& Luckmann, 1978, p. 200).

A família e a escola são, em relação às socializações primária e secundária, responsáveis pela individuação do sujeito. Contudo, cabe aqui questionar a distinção entre a socialização primária e a socialização secundária no contexto das transformações da sociedade moderna. Com a entrada da mulher no ambiente público do trabalho, as relações familiares se modificaram. As crianças têm ido cada vez mais cedo para os ambientes escolares e algumas funções maternas, antes desenvolvidas apenas no ambiente doméstico, passaram a ser desempenhadas também por outras pessoas que não a mãe ou pelo ambiente público. Desta forma, embora a família ainda tenha primordial importância na formação do indivíduo, a escola tem ganhado cada vez mais espaço na socialização primária das crianças.

Segundo Winnicott (1982), a escola pode inclusive fornecer oportunidades, em alguns casos, para que a criança supere alguns fracassos maternos, desde que a falha ambiental não seja muito grave. Apoiada na função do professor, especialmente desenvolvida de modo a criar uma atmosfera emocional satisfatória, a escola "pode fornecer oportunidade para uma profunda relação pessoal com outras pessoas que não os pais" (Winnicott, 1982, p. 217).

A escola, como instituição, pode contribuir no processo de formação e fortalecimento do indivíduo para resistir contra a violência e a barbárie. No texto "Educação após Auschwitz", Adorno (1995) argumenta que a educação deve intervir nas estruturas de poder e uma das formas é voltar-se à formação de crianças. A escola - como locus de educação infantil - é um campo privilegiado de formação e reflexão, podendo promover a individuação das pessoas. Para o autor
A educação só teria algum sentido como educação para uma auto-reflexão crítica. Mas como, segundo os conhecimentos da psicologia profunda, o conjunto dos traços de caráter, mesmo no caso daqueles que perpetram os crimes em idade posterior, constitui-se já na primeira infância, a educação que pretenda impedir a repetição daqueles fatos monstruosos deve concentrar-se nessa etapa de vida (Adorno, 1995, p. 107).

A educação escolar tem sido o meio privilegiado de busca da formação, especialmente da instrumentalização para o trabalho. Contudo, a formação ultrapassa e deve ultrapassar os limites dos muros escolares, já que provém de um processo de reflexão individual que, muitas vezes, o sujeito adquire em suas relações sociais extra-escolares. De acordo com o autor citado

(...) a formação cultural é justamente aquilo para o que não existem à disposição hábitos adequados, ela só pode ser adquirida mediante esforço espontâneo e interesse, não pode ser garantida simplesmente por meio de freqüência de cursos, e de qualquer modo estes seriam do tipo 'cultura geral'. (Adorno, 2000, p. 64).

Embora a escola se esforce para garantir a manutenção de sua existência, utilizando o professor como ator principal desta obra, ela está inserida e integra a cultura, sendo cercada por muros porosos às influências sociais. Assim, "enquanto a sociedade gerar a barbárie a partir de si mesma, a escola tem apenas condições mínimas de resistir a isso" (Adorno, 2000, p. 116), auxiliando muitas vezes para a perpetuação da barbárie e do preconceito.

$\mathrm{Na}$ sociedade burguesa, faz-se notória a dificuldade de formação, na acepção legítima do conceito, assim como notórios são os obstáculos ao desenvolvimento da cultura e da educação escolar. No entanto, é preciso entender que ainda assim a escola pode desempenhar um papel bastante importante na luta contra a barbárie, podendo ser uma instituição de resistência, se se apropriar de sua função social latente. Segundo o autor referido

(...) é preciso contrapor-se à barbárie principalmente na escola. Por isso, apesar de todos argumentos em contrário no plano das teorias sociais, é tão importante do ponto de vista da sociedade que a escola cumpra sua função, ajudando, que se conscientize do pesado legado de representações que carrega consigo (Adorno, 2000, p. 117).

Assim, torna-se tarefa principal da educação apontar as contradições e irracionalidades existentes no processo social, possibilitando aos indivíduos quebrarem as amarras sociais que aprisionam a espontaneidade humana.

Nesse sentido, as crianças tornam-se os sujeitos privilegiados para uma formação de base reflexiva. Consoante com a teoria crítica, em que pesem diferenças constatáveis, é a teoria social do psiquismo elaborada por Henri Wallon que ressalta a função social da escola e da educação na formação da personalidade. Nas análises de Wallon, a escola, como instituição e meio de socialização, 
é retratada em sua funcionalidade de forma mais explícita do que nos textos frankfurtianos. Assim, algumas questões sobre escola valem a pena serem discutidas de acordo com o aporte teórico de Wallon.

Henri Wallon (1975), educador francês, apóia sua teoria social do psiquismo no materialismo dialético, admitindo-o como a concepção filosófica que supera as antinomias para a compreensão da realidade, especialmente para o entendimento do desenvolvimento do homem. Seus estudos analisam a criança em suas relações com o meio ambiente, que o autor distingue entre meio físico e social.

A consciência do eu e seu desenvolvimento estão intimamente ligados à percepção que o indivíduo tem do meio em que está inserido. Para o indivíduo, o outro é caracterizado desde as primeiras etapas de desenvolvimento. De início, ocorre uma total dependência do meio externo, especialmente da mãe e dos que o cercam, dos quais o bebê recebe significados e respostas para suas necessidades, sem a delimitação clara entre o eu e o outro. Aos poucos, ocorre a diferenciação e o reconhecimento do outro. Posteriormente, o eu e o outro internalizados serão elementos permanentes da vida psíquica, conceito que Wallon denominou de "socius" ou "alter" (Wallon, 1975).

Para Wallon, a formação da consciência do eu se dá na relação com o outro, em grupos e meios diferentes. Nas palavras do autor: "o grupo é indispensável à criança não só para sua aprendizagem social, mas também para o desenvolvimento da sua personalidade e para a consciência que pode tomar dela" (Wallon, 1975, p. 174).

O grupo - com seus objetivos determinados que orientam as relações e as ações de seus componentes é "(...) o veículo iniciador de práticas sociais. Ultrapassa as relações puramente subjetivas de pessoa para pessoa" (Wallon, 1975, p. 178).

A família, para o autor, é ao mesmo tempo o primeiro grupo social e o meio funcional, no qual a criança é inevitavelmente inserida. Por seu caráter estrito e afetivo, a relação familiar gera um estado de semiconfusão e conflito íntimo para as crianças. Tais conflitos são, durante certo tempo, necessários para que as crianças consigam estabelecer relações harmônicas, posteriormente (Wallon, 1975).

Caracterizada como um meio, a família satisfaz as necessidades básicas das crianças de acordo com seus modos próprios de funcionamento, pois é onde a criança atinge suas primeiras conquistas sociais. Nos grupos familiares, cada membro desempenha um papel determinado e ocupa um lugar específico nas relações estabelecidas, ou seja

A ação que a família tem sobre a criança é o resultado da sua estrutura que não pode suportar amputações nem desvios sem trazer conseqüências mais ou menos graves para cada um dos seus membros. Ela contém papéis essenciais: o do pai e o da mãe, por exemplo, que dificilmente se podem substituir (Wallon, 1975, p. 168)
A ausência paterna e/ou materna ${ }^{1}$ gera implicações específicas ao grupo familiar. Por exemplo, quando da ausência ou desaparecimento do pai, a família pode passar por problemas, como disputa do papel de autoridade; já a ausência materna pode levar a problemas afetivos (Wallon, 1975). No caso da ausência materna pela prisão, o grupo familiar é atingido por outros aspectos, como o estigma social, que podem influenciar as relações posteriores e a inserção de seus membros em outros grupos e meios.

Wallon (1975) defende a idéia de que a criança não deve sofrer influência exclusiva da família e que ela precisa, o quanto antes, entrar em outros meios, tal como a escola, nos quais as relações não sejam intensamente afetivas.

Embora a escola não seja um grupo, mas um meio, ela propicia o surgimento de grupos em seu interior, que podem agir, ou não, de acordo com os objetivos escolares. Para Wallon, a escola, por ser um ambiente coletivo que compreende circunstâncias físicas, humanas e ideológicas, tem um papel fundamental no processo de socialização e formação da personalidade e da consciência individual

Assiste-se aqui [na escola] a uma forma de socialização extremamente nítida: socialização que se traduz pela cooperação, que se traduz igualmente pela exclusão, que se traduz pela rivalidade e que se faz acompanhar duma individualização correlativa (Wallon, 1975, p. 215).

$\mathrm{Na}$ escola, o processo de socialização e individuação caracteriza-se pelo binômio inclusão e exclusão, pois ali as crianças têm a possibilidade de se perceberem como fazendo parte de um grupo e, ao mesmo tempo, serem excluídas de outros.

Um dos aspectos mais importantes da escola, na sociedade atual, é a instrumentalização que ela oferece ao indivíduo para sua inserção no mundo do trabalho, promovendo em última instância a socialização para o trabalho, centrada em uma produção capitalista.

Essas reflexões teóricas servem de base para a compreensão das particularidades da escola, socialização, desenvolvimento e atendimento de crianças excluídas, em especial, os filhos de mulheres presas.

A contradição de uma sociedade que tem em sua base o trabalho e que é fortemente determinada pelo pressuposto do "respeito" à propriedade privada, reflete-se diretamente no processo de socialização e de adaptação de crianças que vivem uma situação social específica. Em particular, cometer um crime significa transgredir as normas sociais e a transgressão aponta para uma não-adaptação e, consequentemente, para uma distinção aos padrões sociais vigentes.

A prisão parental - especialmente a materna alimenta a crença social de que a má conduta possa ser transmitida de pais para filhos. Essa concepção pode mediar as relações estabelecidas por essas crianças, dificultando o

1 Reafirmamos aqui que não se trata necessariamente de pais biológicos, mas de funções parentais. 
seu processo de socialização e individuação, incluindo a sua família de origem e a instituição escolar, tornando-as alvo fácil de preconceito, na acepção anteriormente tratada.

A prisão, com as consequências objetivas e subjetivas impostas à mãe e aos filhos determina, em parte, significados sociais atribuídos a ela, que podem se sobrepor à escolarização dos filhos de mulheres presas, intensificando o impacto que o afastamento materno representa em suas vidas.

\section{Método}

Este trabalho está baseado na coleta de histórias de vida de filhos de mulheres presas, uma vez que permite que o indivíduo relate novos aspectos de seu eu, na medida em que na sua narrativa possa descrever fatos interativos entre a atividade individual e da coletividade (Becker,1999).

Nesse sentido, a técnica de história de vida pode ajudar a entender a noção de processo, tanto na história desenvolvimental do indivíduo quanto no processo social, que aparece aqui como "um processo observável de interação simbolicamente mediada” (Becker, 1999, p. 110).

Assim, os depoimentos foram colhidos e analisados destacando o papel que a escola desempenha ou desempenhou na socialização e individuação destas pessoas.

Os sujeitos são de ambos os sexos, com idades entre 19 e 25 anos, e passaram pela situação de terem suas mães presas durante o processo de escolarização, especialmente no ensino fundamental. A escolha desses sujeitos relaciona-se com as possibilidades de que eles já tenham tido a experiência de um percurso escolar ou, pelo menos, tentativas de ingresso, além de poderem trazer em suas histórias significações daquela época de desenvolvimento. Os sujeitos foram indicados pelas próprias mães que se encontravam presas, no Estado de São Paulo, especificamente na Penitenciária Feminina da Capital, na época da realização da pesquisa.

A amostra foi constituída por quatro rapazes e duas moças, com média de idade de 21 anos, que moravam com a própria mãe ou com a família dela quando da prisão materna.

Com horários previamente agendados, os entrevistados relatavam sua história de vida iniciando desde a infância; as falas eram entremeadas por questões da pesquisadora e visavam elucidar alguns aspectos, aprofundar outros ou então levantar os aspectos temáticos desta pesquisa; muitas questões sociais foram abordadas como, por exemplo, violência, qualidade da escola, preconceito, religiosidade e criminalidade. As entrevistas duraram em média uma hora e trinta minutos cada uma ${ }^{2} \mathrm{e}$ foram realizadas em dois encontros.

2 As entrevistas foram gravadas com a autorização prévia dos entrevistados. A necessidade da gravação das entrevistas ficava clara desde o primeiro contato telefônico. Todas as entrevistas transcorreram sem problemas.
As entrevistas, após uma primeira análise, proporcionaram a especificação de categorias, identificadas como significativas para os sujeitos da pesquisa e para a verificação ou a refutação das hipóteses a princípio levantadas, a saber: 1) se a prisão materna, por seu significado social, influencia a socialização e individuação dos filhos, especialmente, em relação à instituição escolar; 2) se as múltiplas formas de guarda a que a criança pode ser submetida durante a prisão materna, interferem na continuidade de sua escolarização. Diferentes formas de guarda e a mudança de cuidadores podem trazer implicações quanto à mudança de escola, ao abandono do ano letivo e, principalmente, à quebra das relações sociais desenvolvidas no interior da instituição escolar.

Para que o tema pudesse se sobressair, foram realizados recortes no material coletado, orientados pelos referenciais teóricos adotados e também pelos focos de interesse que nortearam a pesquisa. Os nomes dos entrevistados foram trocados por nomes fictícios para evitar a identificação dos sujeitos e suas falas preservadas com os erros coloquiais da linguagem oral.

\section{A história escolar dos sujeitos}

\section{A entrada na escola}

Como já expusemos, a família é a responsável por promover a passagem da socialização primária, que ocorre em seu interior, para a socialização secundária, que ocorre num meio mais amplo e menos afetivo, como a escola. Por meio das falas dos entrevistados, fica evidente que, quando ocorrem problemas na socialização primária, o processo de socialização secundária fica comprometido.

Mas eu acho que, se ela (mãe) tivesse me acompanhado na escola, eu acho que eu já teria terminado os meus estudos, podia tá fazendo uma faculdade, mesmo ela não tendo um estudo pra me ajudar fazer o estudo, mas só de ela estar ali em cima de mim me incentivando, iria me adiantar. (Mara)

[E por que você se desinteressava (pela escola), assim?]

Não sei... acho que não pegava o mesmo... eu acho que eu seguia um ritmo e também... porque eu acho que acontecia coisas na época que fazia com que eu desinteressava (Por exemplo?) Por exemplo, alguma coisa da família, por exemplo, um exemplo familiar mesmo, ou minha vó ficava doente, alguma coisa assim, ai eu desinteressava da escola, não só da escola, mas de muitas coisas... Eu, na escola também, neste mesmo período eu jogava muito futebol, ai parava futebol, parava escola, parava tudo... (Fernando)

A valorização do acompanhamento familiar no processo educacional é uma constante nas fala destes entrevistados. Outro ponto a se ressaltar é a disponibilidade emocional do indivíduo para o envolvimento no processo de aprendizagem. Na fala de Fernando, sua concentração está voltada para outras tarefas, como organizar questões familiares; neste contexto, as propostas educacionais e de convívio social perdiam o significado e a importância. 


\section{O papel materno no percurso escolar dos filhos}

Nas falas de Mara, os papéis do pai e da mãe são significados pelo sujeito como essenciais para a continuidade dos estudos.

Quando ela vinha pra rua, eu já não estava estudando, aí ela ficava no meu pé, volta, volta... Tanto é que um ano ela começou pagar escola pra mim particular, pra mim voltar a estudar, mas... aí eu voltava, ficava três meses na escola, aí acontecia alguma coisa, eu já parava... [- Acontecia alguma coisa com ela?] É, aí eu já parava de estudar (Mara).

Destacam-se aqui valores e atitudes que são apreendidos com os nossos cuidadores primários. Na fala dos entrevistados, parece de fundamental importância, para a formação do indivíduo, que a família apoie e valorize a educação de forma adequada para o bom desenvolvimento do aluno.

Porque escola a gente estuda não só dentro da escola, em casa a gente tem que pegar um livro, um caderno, ver a matéria, estudar em casa também... é necessário um adulto tá Ihe falando, oh! Isto não é assim é assim, isto não é deste jeito é deste jeito e isto dificultou, me dificultou e muito. (João)

Na fala de João, o significado atribuído pela família à socialização pode interferir na valorização ou não pelo aluno de seu percurso escolar.

A escola, por ser um ambiente coletivo, propicia o surgimento de grupos, por meio dos quais os indivíduos podem experimentar a cooperação e a rivalidade, num processo de socialização que se reflete pela inclusão e exclusão (Wallon, 1975). Nos depoimentos dos entrevistados, aparece claramente este processo socializador na inclusão em alguns grupos e na exclusão de outros.

Muitas da vezes influenciado por más companhias, muitas das vezes por bagunça, muitas das vezes porque os poucos amigos que eu tinha, eu tinha que ser que nem eles porque senão eu era como que dispensado, eu era como que descartado daquele determinado grupo, mas isto eu fiz poucas vezes e resolvi não mais fazer isto, entendeu? (João)

Eu acho que... ela [professora] unia tudo, né, ela via, assim... ela percebeu... não esmoreceu... isto no início, aí ela ia fazendo algumas brincadeiras, entende? Ah, hoje eu não vou dar muita lição não porque eles tão meio... ela começou a dar muito trabalho em grupo, aí o grupo se uniu, deixou o grupo se unir, entende? Já que ela viu que o pessoal tava vindo da $1^{a}, 2^{a}$, fazendo a $3^{a}$ tudo junto aí misturou tudo da outra sala, acho que ela pensou são salas diferentes, grupos diferentes que tão vindo, ela começou a fazer muito trabalho em grupo, trabalho pedagogo mesmo, às vezes não tinha nada a ver com a escola, não, tudo tem a ver, com as matérias que ela tava dando, ela pedia pra gente, um grupo de seis, vocês vão ter que ver um desenho aí e fazer um comentário sobre o desenho, fazer tipo o que vocês gostaram do desenho, aí uns gostavam de um desenho, outros gostavam de outro, aí ela ficava aquela aula toda... aí foi aí que ela começou a ter o controle, entende? Aí ninguém desrespeitava ela, na hora que ela começava a falar as coisas todo mundo ouvia, entende? Porque eram coisas que nós gostávamos, entende? Criativo. (Fernando)

Na última fala de Fernando, é destacável a lembrança da escola como positiva, bem como o papel da professora e a atividade que ela propõe. Nota-se, conforme a discussão teórica de Adorno e Wallon, que, na formação do grupo, podem ser encontradas possibilidades de reflexão coletiva, na qual a consciência de si pode-se dar na relação com o outro.

Os discursos dos sujeitos em relação aos professores reafirmamas concepções deWinnicott(1982)eAdorno(2000), ressaltando o papel primordial destes quando propiciam um ambiente onde as reflexões e as conscientizações se fazem presentes. Nas falas dos entrevistados, os professores aparecem com a seguinte simbolização:

[E os professores?]

Ah, os professores na época eu acho que era até mais compreensível, os que sabiam assim, normalmente todos sabem, né. Eles eram bastante compreensível, conversavam e tal, entendeu? Mas nenhum assim falou nada pra mim. Todos que eu me lembro, todos me trataram super bem. (Mara)

[E você percebia preconceito por parte dos professores ou da direção da escola?]

Não, nunca tive, por professores, não. Até pelo contrário, tinha professores que não sei, eles achavam que a gente sentia isto, pensava o aluno deve achar que... eles até ficavam mais próximos da gente, tipo um grupo, não era só eu que era negro, tinha mais alunos, eles chegavam até mais próximos de nós. (- Como assim mais próximos?) Assim... uma explicação de um aula eles achavam é... achavam que a gente não entendeu? Ele vinha mais próximo chegava lá... Ah! por que você não entendeu? Opa, vamos aqui explicar, terminava a aula ele na hora de sair tentava conversar, não só sobre a escola, entende? Queria saber da vida? $E$ eu percebia que não era com todos assim, era um, dois professores assim... eles vinham mais seguros, entende? (Fernando)

Esta última fala de Fernando apresenta uma relação de cuidado do professor em relação ao aluno, como a representação da figura parental atribuída socialmente ao professor.

A precariedade e sucateamento da instituição escolar a que assistimos hoje, especialmente nas escolas públicas de ensino, também compõem as lembranças dos entrevistados sobre a escola.

Aí me colocaram pra estudar à tarde, chegava meio-dia na escola, mó solão quente, a sala sem cortina, não tinha ventilador, não tinha nada e fazendo... Aí não gostava de ficar dentro da sala. Aí o professor: o que você vai fazer lá fora? Ah, tô com falta de ar. Eu tenho um pouco de falta de ar: tô com falta de ar, não consegui ficar dentro da sala, não, tá tudo abafado, não tem um ventilador. (Pedro) 
[Fernando, o que você acha da educação hoje?]

Eu acho que tá diferente, o aluno só precisa ir na escola só, não precisa de nota, coisa assim... o professor ele tá meio que sem valor, eu acho, neste caso, eu acho que naquela época ali o professor tinha mais valor, eu acho... ou ele prestava atenção ou ele repetia, né? Agora eu posso ir pra escola, posso ir lá, atrapalhar a vida do professor o ano inteiro e passar de ano. Aí, o que acontece? O professor fala, já que ele vai mesmo passar de ano pra que que eu vou ficar me matando, passando horas e horas preparando aula, pra chegar aqui e não conseguir dar a minha aula, eles vão passar mesmo, então eu acho que isto prejudica um pouquinho a educação, o estudo, se vê pessoas aí na $6^{a}$ série, $7^{a}$ série que coisas de tabuada se complica um pouco, né, até pra lê, você pede pra pessoa ler, um negócio aí, a pessoa fica, aaa teeem... entende? (Fernando)

De acordo com as falas de Pedro e Fernando, tanto as condições ambientais como as políticas educacionais vigentes trazem complicadores para o processo de aprendizagem.

Outro aspecto é que muitas vezes a escola está preparada para lidar com o aluno ideal e não consegue entender as necessidades de seus alunos reais, que acabam por se rebelarem. A escola, nesse processo, toma a opção por expulsar ou negligenciar aquele aluno que não se encaixa nos padrões esperados.

Aí ela chamava a atenção, né? Colocou lá num livro preto e ia mandar pra diretora. Não resolveu nada, aí no outro dia, os moleques me xingando, xingando, de novo, eu falei pra professora, a professora não resolveu. Eu falei, ah, já que a senhora é a professora aqui não resolve nada, né. Se os moleques me xinga eu vou resolvê tudo no braço. Moleque me xingando, tacando papelzinho, colocando papelzinho no tubo de caneta e assoprava em mim. E eu: pára, meu... Pára, o moleque não parou, eu peguei e levantei, do jeito que eu levantei eu peguei na cadeira assim, dei uma cadeirada. Aí a diretora me chamou, falou um monte pra mim, aí falou que ia mandar eu pra delegacia, chegava lá os caras iam me bater tal, aí eu peguei, dei um empurrão na mesa dela, aí pegou no braço dela, deslocou... Aí foi quando eu fui... diz ela, que ela me expulsou da escola, mas só que o diretor lá da FEBEM pediu minha transferência. Aí passei para a sétima série e comecei a estudar à noite... (Pedro)

Muitas vezes, a escola trata os alunos descontextualizando-os de suas relações familiares e sociais. Na seguinte fala de Mara, notamos a omissão da escola quanto ao abandono escolar.

[E quando você saiu da escola, nenhum professor foi visitála? Nem a direção da escola pra saber por que você estava parando?]

Não, não.

[Simplesmente não foi mais e ninguém quis...]

É, ninguém quis saber por que eu deixei de ir.
[E os amigos não perguntaram, porque assim... não se, mas normalmente a gente mora perto da escola, né?]

É...

[E aí os amigos da escola acabam sendo nossos vizinhos.]

É por aí... a gente encontra, alguns perguntaram... ah, você faz a maior falta na escola... por que você parou?... Sei lá, perdi o pique, sei lá, não tenho mais vontade de ir, sei lá, pra ficar ouvindo... coisas, prefiro ficar em casa. Ai tinha amigos que falavam assim: pó, volta... e eu: não, não vou voltar. (Mara)

Destaca-se na fala dos entrevistados que a escola é muito importante, não só pela convivência social que proporciona, mas também pela instrumentalização que promove para plena inserção social, incluindo o mundo do trabalho; em alguns casos, porém, ela se omite, principalmente, quando não particulariza seus alunos.

\section{Discussão}

Com certeza, este é um campo de conhecimento que apenas foi inaugurado. Muitos estudos podem e devem ser realizados, especialmente nas áreas de Psicologia e Educação, para contribuir ao atendimento não só de filhos de mulheres presas, mas também de crianças que não se enquadram nos padrões sociais vigentes, auxiliando assim para que a escola desenvolva plenamente seu papel na inclusão social.

$\mathrm{Na}$ história escolar dos filhos de mulheres presas entrevistados, podemos destacar vários aspectos, tais como: a valorização que os sujeitos fazem do processo escolar como meio de inclusão no mercado de trabalho e ascensão social; a importância do acompanhamento familiar na escolarização, especialmente o materno; a precariedade da escola pública; o papel do professor e a formação de grupos em seu interior, bem como possíveis inclusões e exclusões.

Mesmo sendo esta uma pesquisa pioneira sobre o tema e muitos aspectos aqui somente mencionados mereçam um aprofundamento, algumas considerações podem ser feitas sobre o impacto do aprisionamento materno na vida escolar e desenvolvimento dos filhos de mulheres presas.

A prisão materna pode deixar a criança em situação de vulnerabilidade, o que reflete em sua socialização secundária; interferência que, na socialização promovida pela escola, pode assumir vários aspectos, tais como: a criança pode estar emocionalmente tão envolvida com questões de ordem familiar que apresenta pouca disponibilidade e energia para o seu processo de aprendizagem; pode também não ter um acompanhamento sistemático do seu desenvolvimento escolar, já que talvez não possua um adulto significativo que apóie e valorize sua escolarização. Cabe ressaltar que o acompanhamento escolar dos filhos na sociedade atual ainda está relacionado a funções maternas. 
Os filhos de mulheres presas, entrevistados para esta pesquisa, atribuem importância à escolarização, atrelam a ela a sua instrumentalização para o mercado de trabalho e uma consequente ascensão social e culpabilizam a prisão materna por seus fracassos escolares.

Desse modo, podemos verificar que o aprisionamento materno influi na escolarização das crianças, especialmente se envolver a mudança do cuidador primário e acontecer na fase escolar da criança.

Contudo, a escola pode oferecer um importante apoio, especialmente emocional, se propiciar relações significativas em seu interior e oferecer um ambiente satisfatório de desenvolvimento e aprendizagem. No caso dos grupos que acolhem filhos de mulheres presas, as escolas poderiam exercitar sua vocação para uma educação emancipatória e reflexiva que auxilie no combate da barbárie e do preconceito. No universo da prisão materna, a mãe pode até ser culpada pelo crime/delito cometido, mas as crianças também acabam sendo punidas pelo afastamento da mãe e pelo impacto que esta prisão provoca em seus desenvolvimentos, especialmente em seus percursos escolares.

\section{Referências}

Adorno, T. (1995). Palavras e Sinais. Petrópolis, RJ: Vozes.

Adorno, T. (2000). Educação e emancipação. São Paulo: Paz e terra.

Becker, H. (1999). Métodos de Pesquisa em Ciências Sociais. São Paulo: Hucitec.
Berger, P., \& Luckmann, T. (1978). A construção social da realidade. Petrópolis, RJ: Editora Vozes.

Bowlby, J. (1995). Cuidados maternos e saúde mental. São Paulo: Martins Fontes.

Fritsch, T., \& Burkhead, J.(1981). Behavioral reactions of children to parental absence due to imprisonment. Family Relations, 30, 83-88.

Gabel, S. (1992). Behavioral problems in son of incarcerated ou otherwise absent fathers: the issue of separation. Family Process, 31, 303-314.

Marshall, W., \& Binkiewic, A. (1992). Children of prisoners. The Pediatric Forum, 146, 902-903.

Secretaria de Administração Penitenciária do Estado de São Paulo. (2002). Censo penitenciário. Recuperado em 03 de agosto de 2009 de http://www.funap.sp.gov.br/faq_censo.htm

Spitz, R. A. (1993). O primeiro ano de vida. São Paulo: Martins Fontes.

Stella, C. (2005). Educação e filhos de mulheres presas: o impacto do aprisionamento materno na história escolar dos filhos. Tese de doutorado, Pontíficia Universidade de São Paulo, São Paulo.

Stella, C. (2005). Filhos de mulheres presas: soluções e impasses para seus desenvolvimentos. São Paulo: LCTE.

Wallon, H. (1975). Psicologia e educação na infância (A. Rabaça, Trad.). Lisboa: Estampa.

Winnicott, D. W. (1982). A criança e seu mundo. Rio de Janeiro: LTC.

Winnicott, D. W. (1995). Privação e delinqüência. São Paulo: Martins Fontes.
Recebido em: 06/08/2007

Reformulado em: 03/07/2009

Aprovado em: 17/07/2009

\section{Sobre a autora}

\section{Claudia Stella}

Professora da Universidade Presbiteriana Mackenzie

Financiado pelo CNPq. 